\title{
PERAN PENYULUH DALAM PEMBELAJARAN INSEMINASI BUATAN KEPADA PETERNAK SAPI DI KECAMATAN KAWANGKOAN BARAT KABUPATEN MINAHASA
}

\author{
Dina M. O. Tulong, F. S. Oley*, J. Lainawa, A. K. Rintjap
}

Fakultas Peternakan Universitas Sam Ratulangi Manado, 95115

\begin{abstract}
ABSTRAK
Tujuan penelitian ini adalah mengkaji bagaimana peran penyuluh dalam pembelajaran inseminasi buatan kepada peternak sapi di Kecamatan Kawangkoan Barat Kabupaten Minahasa yaitu dengan melihat bagaimana peran penyuluh, keberhasilan pembelajaran IB dan hubungan peran penyuluh dengan keberhasilan pembelajaran inseminasi buatan kepada peternak sapi. Pengumpulan data dilakukan dengan wawancara langsung kepada peternak sapi dengan bantuan kuesioner yang diukur berdasarkan skala likert. Analisis data menggunakan rumus index persen untuk penentuan nilai variabel dan analisis korelasi sederhana untuk melihat hubungan variabel peran penyuluh dan keberhasilan pembelajaran inseminasi buatan kepada peternak sapi. Hasil analisis menunjukan penilaian peran penyuluh berada dalam kategori baik dan keberhasilan pembelajaran inseminasi buatan berada dalam kategori berhasil dengan demikian terdapat hubungan antara peran penyuluh dan keberhasilan pembelajaran inseminasi buatan kepada peternak sapi di Kecamatan Kawangkoan Barat Kabupaten Minahasa.
\end{abstract}

Kata kunci : Penyuluh, pembelajaran inseminasi buatan, peternak sapi.

*Korespondensi (corresponding author) Email : anneke_rintjap@yahoo.com
ABSTRACT

ROLE OF INSTRUCTOR ON
ARTIFICIAL
LESSON TO CATTLE FARMERS IN
WEST KAWANGKOAN DISTRICT
MINAHASA REGENCY. ThS PUINATION
MINAHASA REGENCY. The purpose of this study was to examine how the role of instructors in learning artificial insemination to cattle farmers in West Kawangkoan District, Minahasa Regency, that is by looking at the role of extension agents, the success of IB learning and the role of extension agents with the success of artificial insemination learning to cattle farmers. Data collection was carried out by direct interviews with cattle breeders assisted by questionnaires. Data analysis using index percent formula for determining variable values and simple correlation analysis to see the relationship between the role of instructor variables and the success of artificial insemination learning to cattle farmers. The results of the analysis show that the role of the instructor is in good category and the success of learning artificial insemination is in the successful category, so there is a relationship between the role of instructor and the success of artificial insemination learning to cattle farmers in West Kawangkoan District, Minahasa Regency.

Keywords: Role of instructor, learning of artificial insemination, cattle ranchers.

\section{PENDAHULUAN}

Menurut perhitungan Kementerian Pertanian RI, total kebutuhan daging sapi di tahun 2016 adalah 490.000 Ton. Produksi daging sapi lokal sudah sebanyak 
2,5 juta ekor atau setara dengan 441.000 Ton, maka kekurangan yang harus dipenuhi adalah 48.000 Ton atau setara dengan 146.000 ekor sapi. Populasi ternak sapi Potong di Kecamatan Kawangkoan Barat menurut data BPS tahun 2017 ialah 2.021 ekor.Inseminasi Buatan merupakan suatu bioteknologi reproduksi dalam upaya meningkatkan produksi ternak sapi dengan sasaran akhir peningkatan pendapatan peternak. Tantangan yang dihadapi oleh bidang peternakan adalah masih sedikit peternak yang profesional dan memanfaatkan teknologi yang ada.Teknologi telah mampu menghasilkan bibit-bibit unggul pada hewan yang dapat menguntungkan manusia, khususnya dalam bidang bioteknologi. Kegiatan peternakan di Indonesia sebagian besar masih merupakan usaha peternakan berskala kecil atau usaha ternak rakyat. Tantangan terbesar untuk mencapai keberhasilan pembangunan peternakan adalah bagaimana mendorong dan menumbuh kembangkan agar peternak menjadi lebih berkualitas. Menurut Rintjap et al.(2015) pada umumnya usaha peternakan sapi potong di Kabupaten Minahasa masih bersifat ekstensif, dimanaternak sapi dilepas pada siang hari dilahan perkebunan dan pada malam hari dibawa pulang ke rumah untuk dikandangkan. Kandang yang dibuat sangat sederhana, yang pada prinsipnya bisa melindungi ternak sapi dari cuaca dan aman dari pencurian ternak.Jenis ternak sapi yang dipelihara adalah sapi PO, sapi Sumba dan sapi Bali. Peningkatan usaha ternak sapi potong di Kabupaten Minahasa diperlukan penerapan teknologi.Dalam pengembangan teknologi inseminasi buatan perlu adanya kegiatan yang menumbuh kembangkan kualitas peternak dengan melaksanakan kegiatan pendidikan non formal atau penyuluhan. Penyuluhan merupakan suatu aktivitas kegiatan proses pembelajaran, maka keberhasilannya akan sangat berpengaruh pada sejauh mana proses pembelajaran tersebut berlangsung dengan baik. Disinilah peran penyuluh sebagai seorang ahli yang diberi tanggung jawab dalam melaksanakan kegiatan penyuluhan dan pembelajaran berperan penting. Metode yang digunakan dalam penyuluhan hendaknya bersifat mendidik, membimbing dan menerapkan, sehingga peternak dapat menolong dirinya sendiri, merubah pola pikir, cara bekerja dan kesejahteraannya. Penyampaian informasi secara lengkap dan efektif dibutuhkan perencanaan yang baik, pengambilankeputusan, isi pesan penyuluhan, metode penyuluhan atau kombinasinya yang digunakan dan cara penggunaannya. Permasalahan di lapangan berkaitan dengan pembelajaran inseminasi 
buatan adalah kurangnya antusias peternak dalam mengikuti kegiatan yang berkaitan dengan pembelajaran inseminasi buatan, hasil inseminasi buatan tidak sesuai dengan apa yang diharapkan oleh peternak atau kurang baik, peternak yang cenderung lebih menyukai perkawinan secara alami pada sapi dibandingkan dengan menggunakan teknologi inseminasi buatan.Peran penyuluh dalam hal ini sangatlah berdampak pada keberhasilannya pembelajaran inseminasi buatan kepada peternak sapi di Kecamatan Kawangkoan Barat Kabupaten Minahasa.Jika peran penyuluh kurang baik, maka penyuluh harus meningkatkan dan memperbaiki kinerjanya, sebaliknya jika peran penyuluh dinilai sudah baik, berarti penyuluh tersebut sudah menjalankan tugas dan fungsinya dengan baik. Dapat disimpulkan semakin baik peran seorang penyuluh maka akan semakin baik pula proses pembelajaran Inseminasi Buatan kepada peternak sapi. Berdasarkan hal-hal yang telah dikemukakan maka akan dilakukan penelitian yang berjudul "Peran Penyuluh Dalam Pembelajaran Inseminasi Buatan Kepada Peternak Sapi Di Kecamatan Kawangkoan Barat Kabupaten Minahasa”.

\section{METODE PENELITIAN}

Penelitian ini dilaksanakan pada tanggal 15 juli sampai dengan 14 agustus
2018 di Kecamatan Kawangkoan Barat Kabupaten Minahasa. Penelitian ini berbentuk survey dan merupakan jenis penelitian kualitatif yaitu penelitian yang bersifat menjelaskan bagaimana peran penyuluh terhadap proses pembelajaran inseminasi buatan kepada peternak sapi di Kecamatan Kawangkoan Barat Kabupaten Minahasa.Populasi dalam penelitian ini yaitu seluruh peternak sapi potong yang berada di Kecamatan Kawangkoan Barat khususnya Desa Kanonang Satu, Kanonang Dua, Kanonang Empat dan Kanonang Lima dan seluruh penyuluh yang pernah bertugas di desa tersebut. Penentuan sampel ditentukan secara sengaja (purposive) yaitu suatu metode yang berdasarkan atas pertimbanganpertimbangan tertentu. Dasar pertimbangan yang dipakai dalam menentukan sampel adalah desa yang memiliki populasi ternak sapi terbanyak dan desa yang pernah mendapatkan penyuluhan atau adanya kegiatan inseminasi buatan yaitu Desa Kanonang Satu dan Desa Kanonang Dua. Jumlah populasi peternak yang pernah mengikuti kegiatan inseminasi buatan dikedua desa sampel ini adalah 52 peternak sapi yaitu 32 peternak di Desa Kanonang Satu dan 20 peternak di Desa Kanonang Dua dengan jumlah sampel yang diambil sebanyak 34 orang peternak sapi. Pemilihan responden 
yang berjumlah 34 orang digunakan rumus slovin dengan toleransi kesalahan sebesar $10 \%$. Total responden untuk peternak dalam penelitian ini didapat sebanyak 34 orang dalam kedua desa. Sampel penyuluh ditentukan berdasarkan total sampling dengan memilih penyuluh yang pernah bertugas pada sampel desa terpilih yaitu 2 orang. Menurut Sugiyono (2010) pada prinsipnya meneliti adalah melakukan pengukuran, maka harus ada alat ukur yang baik. Alat ukur dalam penelitian biasanya dinamakan instrumen penelitian.Jadi instrumen penelitian adalah suatu alat yang digunakan mengukur fenomena alam maupun sosial yang diamati.Secara spesifik semua fenomena ini disebut variabel penelitian. Variabel yang akan diukur dijabarkan menjadi sub variabel, kemudian menjadi indikator variabel dan menjadi parameter. Cara pengukuran untuk masing-masing pertanyaan dilakukan dengan menggunakan skala likert.Skala likert digunakan untuk mengukur sikap, pendapat, dan persepsi seseorang atau kelompok orang tentang fenomena sosial Sugiyono (2010). Untuk analisis data, hasil interpretasi responden peran penyuluh dan keberhasilan pembelajaran IB kepada peternak sapi di Desa Kanonang Satu dan Desa Kanonang Dua Kecamatan Kawangkoan Barat dihasilkan dengan menggunakan rumus index $\%(\mathrm{P})$ menurut Sugiyono (2010). Untuk analisis hubungan variabel peran penyuluh dengan pembelajaran inseminasi buatan kepada peternak sapi menggunakan analisis data deskriptif, yaitu suatu metode atau cara menganalisis dan menguraikan data penelitian yang ada dan dikaitkan dengan teori-teori yang ada.

\section{HASIL DAN PEMBAHASAN}

\section{Penilaian Peran Penyuluh}

Penyuluh yang menjadi responden dalam penelitian ini berjumlah dua orang yang merupakan desa sampel penelitian yaitu Desa Kanonang Satu dan Desa Kanonang Dua dari populasi yang tersebar di 4 Desa di Kecamatan Kawangkoan Barat.Rincian mengenai penilaian peran penyuluh berdasarkan parameter yang diukur disajikan dalam tabel 1. Tabel 1 menunjukan bahwa parameter peran penyuluh ditinjau dari beberapa aspek, peran penyuluh yang dinilai sudah baik yaitu kemampuan penguasaan materi dan prinsip-prinsip belajar, pemberian motivasi, kemampuan dalam melakukan IB dan penguasaan teknik IB. 
Tabel 1.Distribusi Penilaian Peran Penyuluh Berdasarkan Parameter

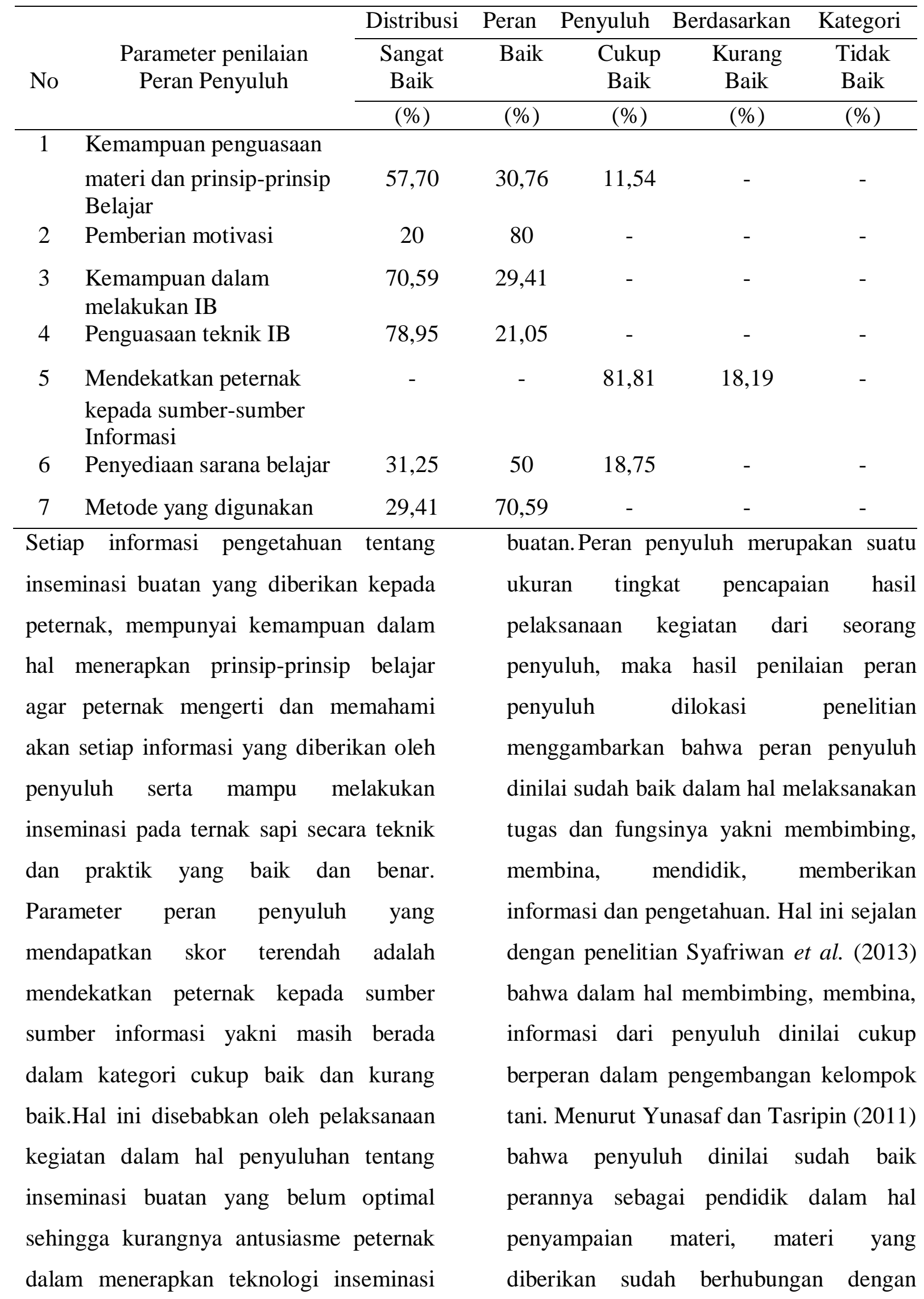


pengetahuan peternak, dan kemampuan dalam menjelaskan materi. Hal ini berarti bahwa peran penyuluh dalam hal membimbing dan mendidik sangatlah penting dan berpengaruh dalam suatu kegiatan penyuluhan dan ikut menentukan baik buruknya kompetensi seorang penyuluh. Hasil keseluruhan peran penyuluh di Desa Kanonang Satu dan Desa Kanonang Dua Kecamatan Kawangkoan Barat Kabupaten Minahasa berada dalam kategori baik, namun juga terdapat beberapa parameter yang berada dalam kategori cukup baik sehingga perlu ditingkatkan mengenai bagaimana seorang penyuluh dapat membantu dan mendekatkan peternak kepada sumbersumber informasi dalam hal ini yaitu membantu peternak mendapatkan semen yang berkualitas, membantu peternak dalam hal mendapatkan modal baik pengetahuan dan dana.

\section{Penilaian Keberhasilan Pembelajaran}

IBKepada Peternak Sapi. Responden peternak sapi dalam penelitian ini yaitu sebanyak 34 orang yang terdapat dalam dua sampel desa dan diambil secara proporsional untuk mendapatkan data yang akurat dan terwakili berdasarkan desa yang berada di Desa Kanonang Satu dan Kanonang Dua Kecamatan Kawangkoan Barat. Rincian data keberhasilan pembelajaran IB kepada peternak sapi di Desa Kanonang Satu dan Desa Kanonang Dua Kecamatan Kawangkoan Barat Kabupaten Minahasa berdasarkan parameter disajikan dalam tabel 2 . Berdasarkan tabel 2 bahwa keberhasilan pembelajaran inseminasi buatan kepada peternak sapi masih terdapat beberapa peternak yang masih dalam kategori kurang berhasil bahkan ada yang berada dalam kategori tidak berhasil. Hal ini disebabkan oleh kurangnya antusiasme peternak akan teknologi inseminasi buatan yang menurut hasil wawancara dengan peternak yakni peternak yang cenderung kecewa dengan hasil dari kawin buatan atau inseminasi buatan, peternak yang masih memilih kawin alam pada ternak sapi dibandingkan dengan teknologi inseminasi buatan. Hal ini berdampak pada peningkatan populasi dengan menggunakan teknologi inseminasi buatan yang masih kurang dibandingkan dengan peningkatan populasi ternak sapi dengan cara kawin alam. Secara umum penilaian keberhasilan pembelajaran inseminasi buatan pada ternak sapi berdasarkan pertanyaan menunjukan nilai yang bervariasi, sebagian besar $(41,18 \%)$ berkategori sangat berhasil yakni dalam parameter meningkatnya pengetahuan peternak akan teknologi inseminasi buatan, 
Tabel 2.Distribusi Keberhasilan Pembelajaran IB Kepada Peternak Sapi Berdasarkan Pertanyaan Pada Setiap Parameter.

\begin{tabular}{|c|c|c|c|c|c|c|c|}
\hline \multirow{3}{*}{ No } & \multirow{3}{*}{ Parameter } & \multirow{3}{*}{ Pertanyaan } & \multicolumn{5}{|c|}{ Kategori Nilai } \\
\hline & & & $\begin{array}{l}\text { Sangat } \\
\text { Berhasil }\end{array}$ & Berhasil & $\begin{array}{l}\text { Cukup } \\
\text { Berhasil }\end{array}$ & $\begin{array}{l}\text { Kurang } \\
\text { Berhasil }\end{array}$ & $\begin{array}{l}\text { Tidak } \\
\text { Berhasil }\end{array}$ \\
\hline & & & $(\%)$ & $(\%)$ & $(\%)$ & $(\%)$ & $(\%)$ \\
\hline \multirow[t]{3}{*}{1} & Meningkatnya & & & & & & \\
\hline & pengetahuan peternak & 1 & 41,18 & 32,35 & 14,70 & 11,77 & - \\
\hline & tentang IB & 2 & 41,18 & 32,35 & 17,64 & 8,83 & - \\
\hline \multirow[t]{2}{*}{2} & Kemampuan peternak & 3 & - & - & 52,94 & 32,35 & 14,71 \\
\hline & melakukan IB & 4 & 17,65 & 44,12 & 29,41 & 8,82 & - \\
\hline \multirow[t]{2}{*}{3} & Meningkatnya & 5 & 17,65 & 32,35 & 26,48 & 23,52 & - \\
\hline & $\begin{array}{l}\text { antusiasme peternak } \\
\text { akan IB }\end{array}$ & 6 & - & 5,88 & 41,18 & 35,30 & 17,64 \\
\hline 4 & $\begin{array}{l}\text { Meningkatnya populasi } \\
\text { ternak sapi dengan } \\
\text { adanya program IB }\end{array}$ & 7 & - & 2,95 & 23,53 & 47,05 & 26,47 \\
\hline
\end{tabular}

Aspek yang kurang berhasil dengan persentase tertinggi $(47,05 \%)$ yakni pada pertanyaan dalam parameter meningkatnya populasi ternak sapi dengan teknologi inseminasi buatan dimana dari hasil wawancara langsung kepada peternak mereka lebih memilih meningkatkan populasi ternak dengan cara kawin alam dibandingkan dengan menggunakan teknologi IB dan jikalau ada ternak dari hasil kawin buatan mereka selalu menjualnya kembali sehingga populasi ternak sapi dengan hasil kawin buatan atau inseminasi buatan dinilai cukup kurang atau kurang berhasil. Hal ini sejalan dengan penelitian Mahalubi et al. (2019) yang mengatakan produktivitas ternak sapi dengan inseminasi buatan dinilai berada pada kategori cukup baik dan tidak baik yang disebabkan oleh kurangnya antusiasme peternak akan teknologi inseminasi buatan, yakni peternak yang cenderung kecewa dengan hasil kawin buatan. Secara keseluruhan penilaian keberhasilan pembelajaran inseminasi buatan kepada peternak sapi di Desa Kanonang Satu dan Desa Kanonang Dua Kecamatan Kawangkoan Barat dalam kategori baik atau berhasil. Hal ini menjadi suatu kebanggaan tersendiri bagi peternak dan penyuluh walaupun masih ada beberapa aspek yang dinilai masih kurang baik dan belum berhasil dalam pengembangan teknologi inseminasi buatan. Upaya peningkatan keberhasilan pembelajaran inseminasi buatan di Desa Kanonang Satu dan Desa Kanonang Dua Kecamatan Kawangkoan Barat dapat dilakukan dengan suatu strategi yang mampu mendongkrak keberhasilan 
peternak maupun pemerintah yang diharapkan dapat meningkatkan populasi ternak sapi dan meningkatkan teknologi inseminasi buatan. Sehubungan dengan hal tersebut Priyanto (2011) mengatakan salah satu strategi dalam pengembangan usaha perlu adanya koordinasi antarinstitusi dari tingkat pusat sampai daerah dalam implementasi program di lapangan.Koordinasi tersebut meliputi perencanaan dan implementasi program, keterkaitan dan tanggung jawab masingmasing institusi, serta pemantauan dan evaluasi secara periodik. Narsoet al. (2012) mengatakan beberapa strategi pengembangan peran penyuluh pertanian lapangan yakni peningkatan kualitas SDM penyuluh dengan mengikuti diklat dari instansi lain untuk menambah kemampuan, pengetahuan dan keterampilan, peningkatan kualitas penyuluh dan sinergitas antar instansi terkait dengan adanya kejelasan tugas pokok dan fungsi, serta pemanfaatan teknologi yang mendukung dan memperlancar pelaksanaan program penyuluhan.Perlu adanya langkah efektif yang dapat ditempuh dalam rangka mempercepat proses pembangunan peternakan yakni dengan melakukan pengembangan peternak melalui program pembangunan peternakan. Menurut Dali et al. (2017) program pembangunan peternakan yang dimaksud merupakan rangkaian upaya perwujudan pembangunan peternakan yang mampu meningkatkan kesejahteraan peternak, agar dapat berjalan lancar membutuhkan adanya kegiatan penyuluhan atau pendidikan tentang pembangunan.

\section{Analisis Hubungan Peran Penyuluh Dengan Keberhasilan Pembelajaran Inseminasi Buatan Kepada Peternak Sapi.}

Hasil analisis hubungan peran penyuluh dengan keberhasilan pembelajaran inseminasi buatan kepada peternak sapi Kecamatan Kawangkoan Barat Kabupaten Minahasa menunjukan bahwa terdapat hubungan antara peran penyuluh dengan keberhasilan pembelajaran IB. Hal ini dibuktikan dari hasil penilaian peran penyuluh dan keberhasilan pembelajaran inseminasi buatan kepada peternak sapi yang berada dalam kategori baik dan berhasil. Hal tersebut berarti bahwa tinggi rendahnya peran penyuluh berpengaruh terhadap pembelajaran inseminasi buatan kepada peternak sapi, semakin baik peran penyuluh semakin baik pula hasil yang dicapai dalam pembelajaran inseminasi buatan kepada peternak sapi. Keberhasilan peternak sangat ditentukan oleh pendidikan yang diterima dari kegiatan penyuluhan yang di dalamnya terdapat seorang penyuluh yang harus memiliki peranan penting dan sangat baik dalam 
melaksanakan tugas pokok dan fungsinya. Hasil penelitian ini sesuai dengan pendapat Far (2014) yang mengatakan bahwa sebagai sistem pendidikan nonformal, penyuluhan pertanian merupakan suatu usaha untuk menimbulkan perilaku peternak seperti perubahan pengetahuan yang lebih luas, perubahan keterampilan teknis yang lebih baik serta perubahan sifat untuk lebih produktif sehingga para peternak dapat memperbaiki cara berusaha ternak agar lebih menguntungkan. Keberhasilan peran penyuluh dalam proses pembelajaran inseminasi buatan di lokasi penelitian salah satunya dalam hal kemampuan penguasaan materi dan prinsip-prinsip belajar dalam hal pemberian informasi pengetahuan mengenai inseminasi buatan kepada peternak, dimana dari hasil wawancara langsung kepada peternak sebagian besar sudah mempunyai pengetahuan dan informasi tentang bagaimana dan seperti apa inseminasi buatan tersebut. Disisi lain berhasilnya peran penyuluh juga dalam hal penyediaan sarana belajar, penguasaan teknik inseminasi buatan dan kemampuan melakukan inseminasi buatan dimana penyuluh sekaligus petugas inseminasi membantu peternak untuk melakukan inseminasi buatan pada sapi dengan menyediakan semen dan alat inseminasi buatan serta secara langsung melakukan inseminasi buatan pada sapi dengan baik. Penyuluh yang bertugas dilokasi penelitian juga selalu memberikan motivasi dan dorongan kepada peternak untuk mau melakukan inseminasi buatan pada ternak sapi mereka, hal ini sejalan dengan penelitian Setiawan (2015) dimana terdapat pengaruh yang signifikan antara motivasi kerja terhadap kinerja seseorang.

\section{KESIMPULAN}

Hasil penelitian menunjukan penilaian peran penyuluh berada dalam kategori baik dan keberhasilan pembelajaran inseminasi buatan berada dalam kategori berhasil dengan demikian terdapat hubungan antara peran penyuluh dan keberhasilan pembelajaran inseminasi buatan kepada peternak sapi di Kecamatan Kawangkoan Barat Kabupaten Minahasa.

\section{DAFTAR PUSTAKA}

Badan Pusat Statistik Kabupaten Minahasa. 2017. Statistik Daerah Kecamatan Kawangkoan Barat.

Dali, I., F. S. Oley, A. K. Rintjap dan J. M. Tumewu. 2017. Hubungan kinerja penyuluh pertanian lapangan dengan keberhasilan peternak sapi potong di Kecamatan Kwandang Kabupaten Gorontalo Utara. Fakultas Peternakan Universitas Sam Ratulangi. Manado. Jurnal Zootek. 37 (2) : 403-414.

Far, R. A. F. 2014.Respon petani terhadap penerapan metode penyuluhan pertanian di Kota Ambon Provinsi 
Maluku. Jurnal Budidaya Pertanian. 10 (1) : 48-51.

Mahalubi, R. I., A. K. Rintjap, J. A. Malingkas dan F. S. G. Oley. 2019. Respon peternak sapi Potong terhadap penerapan teknologi inseminasi buatan (IB) di Desa Tondegesan Dua Kecamatan Kawangkoan Kabupaten Minahasa. Fakultas Peternakan Universitas Sam Ratulangi. Manado. Jurnal Zootek. 39 (1) : 71-81.

Narso., A. Saleh, P. S. Asngari dan P. Muljono. 2012. Strategi pengembangan peran penyuluh pertanian lapangan di Provinsi Banten. Jurnal Penyuluhan. 9 (2) : 116-32.

Priyanto, D. 2011. Strategi pengembangan usaha ternak sapi potong dalam mendukung program swasembada daging sapi dan kerbau tahun 2014. Jurnal Litbang Pertanian, 30 (3) : 108-116.

Rintjap, A. 2015. Efektifitas komunikasi dalam penerimaan informasi pada kelompok peternak sapi potong di Kecamatan Remboken Kabupaten Minahasa. Seminar Nasional Masyarakat Biodiversitas Indonesia. Jurnal Komunikasi. 2 (1) : 1-72.

Setiawan, K. C. 2015. Pengaruh motivasi kerja terhadap kinerja karyawan level pelaksana di Divisi Operasi PT. Pusri Palembang. Jurnal Psikologi Islami. 1 (2) : 43-53.

Sugiyono. 2010. Metode penelitian kuantitatif kualitatif dan r\&d. Bandung: Alfabeta.

Syafriwan., S. Hadi dan Rosnita. 2013. Peranan penyuluh dan strategi peningkatan peranan penyuluh perkebunan dalam pengembangan kelompok tani pemasaran karet di Kabupaten Kuantan Singingi. Jurnal Dinamika Pertanian. 28 (2) : 131-140.

Yunasaf, U. dan D. S. Tasripin. 2011. Peran penyuluh dalam proses pembelajaranpeternak sapi perah di KSU Tandangsari Sumedang. Jurnal Ilmu ternak. 11 (2) : 98-103. 